\title{
Ventricular and pulmonary vascular remodeling induced by pulmonary overflow in a chronic model of pretricuspid shunt
}

\author{
Daniele Linardi, MD, ${ }^{\mathrm{a}}$ Alessio Rungatscher, MD, PhD, FAHA, ${ }^{\mathrm{a}}$ Mohammed Morjan, MD, ${ }^{\mathrm{a}}$ \\ Paolo Marino, MD, ${ }^{\mathrm{b}}$ Giovanni Battista Luciani, MD, ${ }^{\mathrm{a}}$ Alessandro Mazzucco, MD, ${ }^{\mathrm{a}}$ and \\ Giuseppe Faggian, MD $^{\mathrm{a}}$
}

Objectives: Current preclinical models of pulmonary arterial hypertension do not reproduce the clinical char-
acteristics of congenital heart anomalies. Aortocaval shunt is relevant to a variety of clinical conditions. The
pathophysiology and possible determination of pulmonary hypertension in this model are still undefined.

\begin{abstract}
Methods: A method to create a standardized and reproducible aortocaval shunt was developed in rats. After creation of the shunt, the animals were followed up for 20 weeks and a sham laparotomy was used as a control. The chronic effects of volume overload on the right and left ventricles and pulmonary hemodynamic modifications were evaluated by biventricular catheterization, echocardiography, and magnetic resonance. Pulmonary vascular changes were defined by histology.
\end{abstract}

\begin{abstract}
Results: An increased right ventricular end-diastolic area was confirmed by echocardiography. Left ventricular overload and decreased biventricular ejection fraction were demonstrated by magnetic resonance after 20 weeks in the shunt group compared with the controls (left ventricle, $50 \% \pm 5 \%$ vs $62 \% \pm 3 \%, P=.029$; right ventricle, $53 \% \pm 2 \%$ vs $65 \% \pm 2 \%, P=.036$ ). Preload recruitable stroke work of left and right ventricles decreased after 20 weeks in shunt rats (left ventricle: $36 \pm 7$ vs $98 \pm 5, P=.004$; right ventricle: $19 \pm 2$ vs $32 \pm 9, P=.047)$. At the same time point, catheterization showed that effective pulmonary arterial elastance was increased only in the shunt group $(1.29 \pm 0.20 \mathrm{vs} 0.14 \pm 0.06 \mathrm{~mm} \mathrm{Hg} / \mu \mathrm{L} ; P=.004)$. Histology showed medial hypertrophy, small artery luminal narrowing, and occlusion.
\end{abstract}

Conclusions: The aortocaval shunt model reliably produces right ventricular volume overload and secondary pulmonary hypertension. Due to a combination of left ventricular dysfunction and pulmonary overflow, the pulmonary hypertension produced shows features similar to those found in patients with chronic atrial-level shunt. (J Thorac Cardiovasc Surg 2014;148:2609-17)

Left-to-right shunting congenital heart lesions are the most common cause of secondary pulmonary hypertension $(\mathrm{PH})$. The status of the pulmonary vascular structure and $\mathrm{PH}$ are important determinants indicating repair and long-term survival after cardiac surgery.

In children who develop irreversible pulmonary vascular disease in its early stages, pharmacologic therapy is an indispensable strategy for ameliorating life expectancy and creating the opportunity for effective surgery. ${ }^{1}$ Although current pharmacologic treatment protocols effectively reduce the morbidity and mortality of $\mathrm{PH}$ in some patients, none can cure this devastating disease.

Drugs targeting the signaling pathways involved in the pathogenesis of $\mathrm{PH}$ have been confirmed to partially or

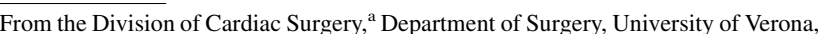
Verona, Italy; and Department of Cardiology, ${ }^{\mathrm{b}}$ University of Novara, Novara, Italy. Disclosures: Authors have nothing to disclose with regard to commercial support. Received for publication Dec 26, 2013; revisions received April 14, 2014; accepted for publication April 24, 2014; available ahead of print June 6, 2014.

Address for reprints: Alessio Rungatscher, MD, PhD, FAHA, Division of Cardiac

Surgery, Department of Surgery, University of Verona, Piazzale Stefani 1, 37126

Verona, Italy (E-mail: alessio.rungatscher@univr.it).

$0022-5223 / \$ 36.00$

Copyright (C) 2014 by The American Association for Thoracic Surgery

http://dx.doi.org/10.1016/j.jtcvs.2014.04.044
}

completely reverse hypoxia and monocrotaline-induced $\mathrm{PH}$ in rats. However, these drugs only exhibited partial improvement in symptoms, exercise tolerance, and hemodynamic indices, with slight efficacy on mortality in patients with severe $\mathrm{PH}^{2}$ This largely attenuated the dogma that hypoxia and monocrotaline-induced $\mathrm{PH}$ models should be used to delineate the potential mechanism of $\mathrm{PH}$, including shunt-related PH. Nevertheless, hypoxia, monocrotaline, or pneumonectomy-plus-monocrotaline models continue to be widely used to investigate the causative mechanisms of PH.

In contrast, there are few studies on shunt-induced $\mathrm{PH}$ models that exactly reproduce clinical $\mathrm{PH}$ related to congenital heart disease.

The mechanisms of $\mathrm{PH}$ with left-to-right shunt are different from those of hypoxia and inflammation. Possible inciting factors of the former are mechanical stretch and shear stress. A shunt from the left innominate artery to the pulmonary arterial trunk was reported to reproduce significant PH. However, this procedure is complex in small animals and it is difficult to control the blood flow, which limits the wider application of a posttricuspid model.

One pretricuspid model, the aortocaval shunt, is relatively widely applied and was first described by Garcia 


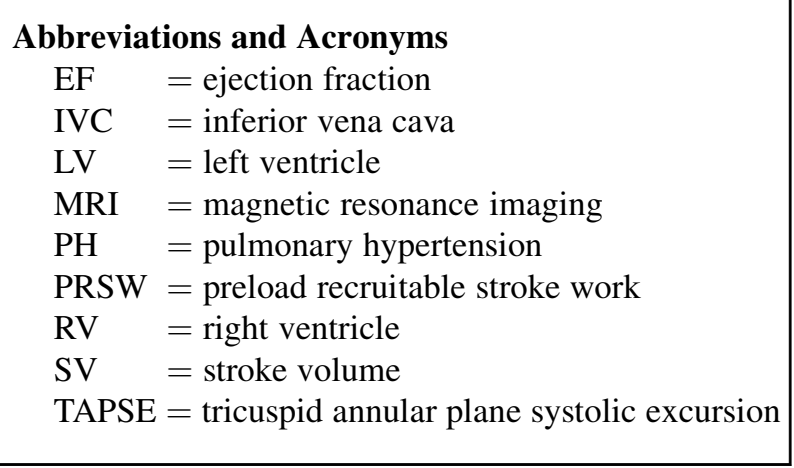

and later modified by others. ${ }^{4,5}$ The aortocaval shunt model was used by several investigators to study right ventricular response to acute, subacute, and chronic volume overload, ${ }^{6-8}$ whereas other investigators used this model to study the effects of increased pulmonary blood flow on pulmonary circulation. ${ }^{9,10}$ However, the results reported in the literature are conflicting, particularly when the model is used to produce secondary $\mathrm{PH}$; the exact mechanism leading to the development of $\mathrm{PH}$ is not clear.

The aim of the present study was to demonstrate the possible induction of secondary $\mathrm{PH}$ as a consequence of chronic exposure to right ventricle (RV) volume overload and pulmonary overcirculation.

In order to explore the hemodynamic and morphometric changes over time after the institution of the shunt, we carried out a detailed investigation using a noninvasive approach with echocardiography and magnetic resonance and an invasive evaluation obtained by hemodynamic assessment of right and left ventricular function. Moreover, a histologic evaluation was provided to document the timerelated structural alterations in small pulmonary arteries.

\section{METHODS}

Male Sprague-Dawley rats (Charles River Laboratories, Calco, Italy) were used ( 8 weeks old, $260 \pm 40 \mathrm{~g}$ ). All experiments were performed in accordance with the Guide for the Care and Use of Laboratory Animals published by the US National Institutes of Health (National Institutes of Health Publication No. 85-23, revised 1996). The protocol was approved by the University of Verona authority for experimental research (C.I.R.S.A.L, Interdepartmental Center of Experimental Research Service). All surgical procedures and the invasive and noninvasive evaluations were conducted under general anesthesia $(0.25 \%$ pentobarbital sodium, $40 \mathrm{mg} / \mathrm{kg}$, intraperitoneal injection).

\section{Surgical Creation of the Shunt}

A midline abdominal incision was made, the abdominal aorta above the renal bifurcation was isolated, and a 3-0 Ti-Cron suture (Covidien, Mansfield, Mass) was positioned around it. The infrarenal portion of the aorta and inferior vena cava (IVC) were exposed at a site where the 2 vessels shared a common fascia. At this site, an 8-0 polypropylene (Ethicon Inc, Johnson \& Johnson, NJ) purse suture was applied on the aorta. The suprarenal portion of the abdominal aorta was then occluded with the 3-0 suture wire positioned to control bleeding. The shunt was then created using an 18-gauge Neo Delta Ven 2 catheter (Delta Med Mantova, Italy), a common peripheral venous catheter, inserted between the purse suture on the anterior surface of the aorta, carefully puncturing the posterior aortic wall up to the adjoining IVC, and then advancing the catheter into the IVC.

The purse suture was then tightened against the catheter and tied on withdrawal of the catheter. The success of the procedure was confirmed after that 3-0 suture wire around the aorta was released by observing the mixing of arterial and venous blood in the IVC with distention and pulsations in the vessel (Figure 1).

The angiocatheter used for shunt creation was measured in preliminary experiments in order to obtain a $\mathrm{Qp} / \mathrm{Qs}$ ratio greater than 2 . Blood samples $(0.5 \mathrm{~mL})$ were obtained from the pulmonary artery, aorta, and superior vena cava after creation of the shunt. Qp/Qs was calculated using the formula $\mathrm{Qp} / \mathrm{Qs}=(\%$ saturation in the aorta $-\%$ saturation in the superior vena cava $) /(\%$ saturation in the pulmonary vein - \% saturation in the pulmonary artery).

\section{Experimental Protocol}

Rats were randomly divided into 3 groups: the first group underwent the shunt procedure and was observed for 10 weeks after the procedure (shunt $10 \mathrm{~W}, \mathrm{n}=10$ ), and noninvasive morphometric and invasive hemodynamic evaluations were performed; the second group underwent the same surgical procedure but was observed for 20 weeks before evaluation (shunt $20 \mathrm{~W}$, $\mathrm{n}=10$ ); the third group underwent a sham laparotomy operation (sham, $\mathrm{n}=10$ ), and then observed for 20 weeks (control group). At the end of the programmed follow-up period, the rats were killed and the samples for histology were collected.

\section{Noninvasive Assessment}

Magnetic resonance. After the established observation period for each group, the rats underwent quantitative magnetic resonance imaging (MRI). All MRI experiments were carried out using a Biospec Tomograph System (Bruker, Karlsruhe, Germany) equipped with a 4.7-T, 33-cm bore horizontal magnet (Oxford Ltd, Oxford, UK). Rats were placed in the prone position in a 7.2-cm transmitter/receiver birdcage coil. Electrocardiographic and respiration rate recordings were continuously monitored by a physiologic monitor for animals compatible with magnetic fields (PCSAM, SAII, Stony Brook, NY).

The imaging session started with the acquisition of 3 fast gradient echo (FLASH) images in order to identify the long and short axis of the heart. Then, cine-FLASH images were acquired in the short axis of the heart with electrocardiographic and respiration gating. Several contiguous slices were acquired in order to cover the whole cardiac volume. Parameters for the cine-FLASH acquisitions were repetition time $=\mathrm{RR}$ interval/number of frames, with typically 20 to 22 frames acquired depending on the cardiac frequency and on the minimum repetition time of the sequence. The number of frames was calculated as number of frames $=$ cardiac period $/$ repetition time. Other parameters were field of view $=6 \times 6 \mathrm{~cm}^{2}$; repetition time $=10$ milliseconds; echo time $=3.6$ milliseconds; slice thickness $=1.5 \mathrm{~cm}$; number of averages $=4$; matrix size $=192 \times 192$ with an in-plane space resolution of $312 \times 312 \mu \mathrm{m}^{2}$.

All the images were analyzed manually using the software tools available in ParaVison 4.0 (Bruker, Karlsruhe, Germany). Volumetric measurements, such as the thickness of the ventricular wall and intraventricular septum, ventricle mass, end-diastolic volume, end-systolic volume, stroke volume (SV), as well as indexes of global ventricular function such as the ejection fraction (EF), were obtained.

Echocardiography. Transthoracic two-dimensional, M-mode, and Doppler (pulse wave and continuous wave) imaging was performed using a Vivid Q General Electronics cardiovascular ultrasound system, with a 10second transducer (from 5 to $7.5 \mathrm{MHz}$ ).

The RV free wall thickness and RV end-diastolic area were assessed in a parasternal short-axis view at the level of the papillary muscles. From an 

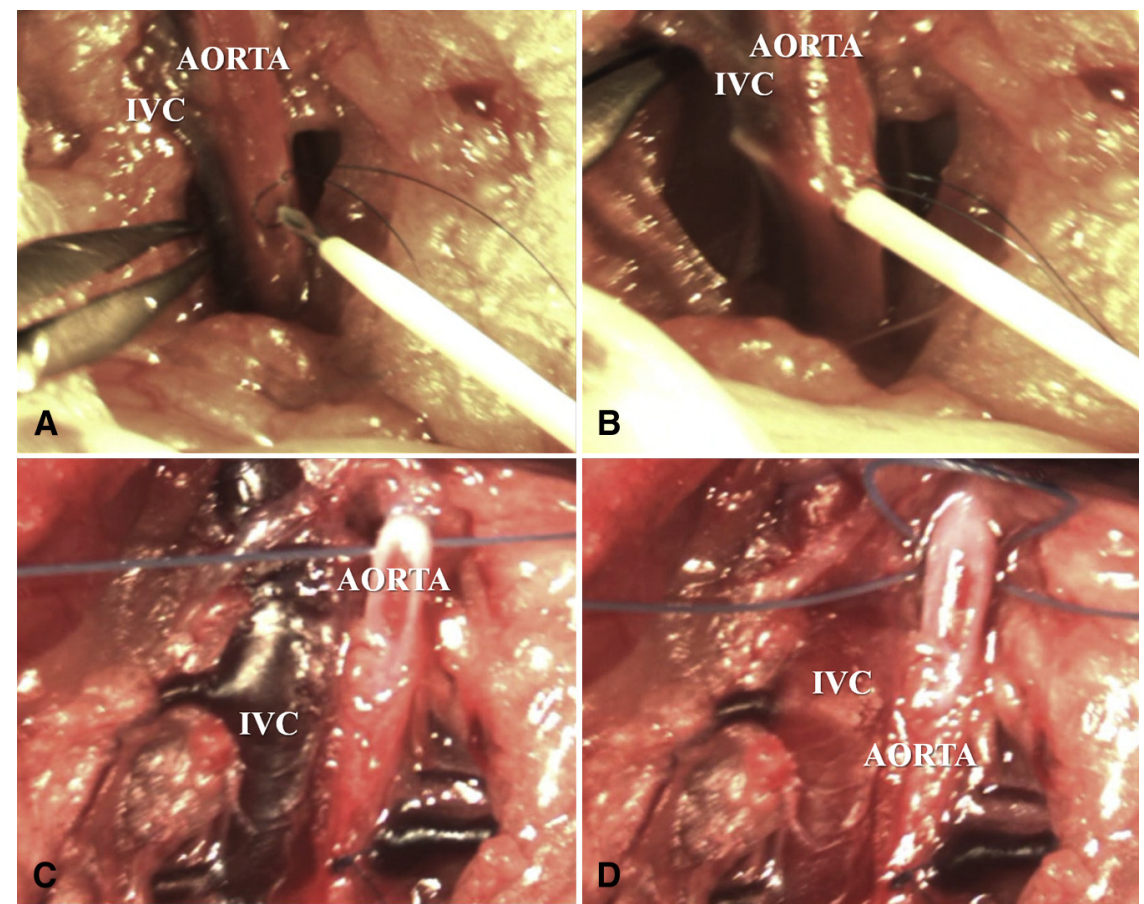

FIGURE 1. A, The infrarenal portion of the aorta and inferior vena cava $(I V C)$ are shown. An 8-0 polypropylene purse suture is applied on the aorta. B, Creation of the shunt: an 18-gauge catheter is inserted between the purse suture on the anterior surface of the aorta and then advanced into the IVC. C and D, The success of the procedure was confirmed by observing mixing of arterial and venous blood in the IVC with distention and pulsations in the IVC.

apical 4-chamber view, an estimate of the tricuspid annular plane systolic excursion (TAPSE) was also obtained.

A continuous wave Doppler echocardiograph of pulmonary blood flow was obtained in parasternal short-axis view, this time at the level of the aortic valve. For the purpose of this study, the development of a mesosystolic notch in the pulmonary artery waveform was considered as a reliable echocardiographic sign of increased pulmonary arterial pressure, in agreement with previous evidence. ${ }^{11}$

\section{Invasive Evaluation}

Rats were placed on a heating pad to maintain normothermia. The trachea was cannulated with a $16-\mathrm{G}$ soft venous cannula and mechanically ventilated with $100 \%$ oxygen at 70 cycles/min with a tidal volume of 7 to $8 \mathrm{~mL} / \mathrm{kg}$ (model 683, Harvard Apparatus, Holliston, Mass).

The right carotid artery was isolated and tied cranially. A 2-Fr miniaturized combined catheter-micromanometer (model SPR 838, Millar Instruments, Houston, Tex) was inserted into the right carotid artery and then advanced into the left ventricle (LV). The correct position of the catheter was checked by the shape of the pressure waveform (from a typical artery shape when placed in the carotid artery and then in the aorta to a ventricular shape when placed in the LV). The signals were recorded continuously at a sampling rate of 1000/s using an ARIA pressure-volume (P-V) conductance system (Millar Instruments) coupled to a PowerLab/4SP A/D converter (AD Instruments; Mountain View, Calif) and a personal computer.

The volume calibration of the conductance system was performed as described previously. ${ }^{12}$ Heart rate, maximal LV systolic pressure, LV end-diastolic pressure, mean arterial pressure, maximal peak systolic pressure increment $\left(\mathrm{dP} / \mathrm{dt}_{\max }\right)$ and diastolic pressure decrement $\left(\mathrm{dP} / \mathrm{dt}_{\min }\right), \mathrm{EF}$, $\mathrm{SV}$, end-diastolic volume, time constant of LV pressure decay (tau, according to the Weiss and Glantz method), ${ }^{13}$ and stroke work (computed as $\mathrm{SV} \times \mathrm{LV}$ pressure integral) were computed using a cardiac $\mathrm{P}-\mathrm{V}$ analysis program (PVAN 5, Millar Instruments). To obtain load-independent parameters such as preload recruitable stroke work (PRSW), P-V relations were measured by transiently occluding the IVC under the diaphragm with a small vascular clamp. ${ }^{14}$

The combined catheter-micromanometer (model SPR 838, Millar Instruments, Houston, Tex) was then inserted into the RV through the jugular vein and the same parameters described previously were recorded. In addition; effective pulmonary arterial elastance (computed as RV end-systolic pressure/SV) was calculated as an index of pulmonary vascular load. The catheter was then slowly advanced into the RV outflow tract and then into the pulmonary artery; pulmonary artery systolic and diastolic pressures were recorded.

\section{Histopathology}

After the rats had been killed, the lungs were rapidly perfused with formalin through the pulmonary artery, inflated through the trachea, and removed. Three pieces of lung tissue from different lobes were excised and immersed in $10 \%$ formalin and sectioned before staining with hematoxylin-eosin and Masson trichrome stains. Ultrastructural changes in intralobular small arteries were examined under a transmission electron microscope by an expert pathologist.

\section{Statistical Analysis}

Data are presented as means \pm standard deviations. Differences between groups were determined using 2-way analysis of variance and the Bonferroni multiple comparison test.

\section{RESULTS}

Four postoperative deaths occurred in the shunt $20 \mathrm{~W}$ group before the end of the follow-up period. A post mortem examination established postoperative heart failure in all 4 cases, with relevant pleural and pericardial effusion.

$\mathrm{Qp} / \mathrm{Qs}$ was $2.12 \pm 0.54$ in the shunt $10 \mathrm{~W}$ group, $1.98 \pm$ 0.41 in shunt $20 \mathrm{~W}$ group, and $1 \pm 0.12$ at 10 and 20 weeks 
TABLE 1. Echocardiographic parameters and general features and major cardiac parameters obtained by magnetic resonance

\begin{tabular}{|c|c|c|c|c|c|}
\hline Parameter & Shunt 10W & $P$ value & Shunt 20W & $P$ value & Sham \\
\hline \multicolumn{6}{|l|}{ Echocardiography } \\
\hline $\operatorname{RV} \operatorname{EDA}\left(\mathrm{cm}^{2}\right)$ & $0.35 \pm 0.06^{*}$ & .024 & $0.36 \pm 0.04^{*}$ & .033 & $0.23 \pm 0.90$ \\
\hline RV WT (cm) & $0.35 \pm 0.05^{*}$ & .042 & $0.33 \pm 0.05^{*}$ & .029 & $0.20 \pm 0.05$ \\
\hline TAPSE $(\mathrm{mm})$ & $1.97 \pm 0.05$ & .062 & $1.93 \pm 0.25$ & .064 & $2.25 \pm 0.05$ \\
\hline MSN & ++++ & & ++++ & & ---- \\
\hline \multicolumn{6}{|l|}{ Magnetic resonance } \\
\hline $\mathrm{RVM} / \mathrm{BW}$ & 0.5 & .069 & 0.4 & .077 & 0.3 \\
\hline LVM/BW & 1.7 & .092 & 1.4 & .089 & 1.3 \\
\hline LV EDV $(\mu \mathrm{L})$ & $589 \pm 52 *$ & .041 & $594 \pm 80^{*}$ & .043 & $530 \pm 11$ \\
\hline $\operatorname{LV~SV~}(\mu \mathrm{L})$ & $333 \pm 6$ & .078 & $302 \pm 18$ & .069 & $330 \pm 5$ \\
\hline $\mathrm{RV} \mathrm{SV}(\mu \mathrm{L})$ & $322 \pm 11^{*}$ & .029 & $245 \pm 7 *$ & .040 & $251 \pm 5$ \\
\hline LV EF (\%) & $56 \pm 7$ & .053 & $50 \pm 5^{*}$ & .029 & $62 \pm 3$ \\
\hline RV EF (\%) & $59 \pm 6$ & .050 & $53 \pm 2 *$ & .036 & $65 \pm 2$ \\
\hline
\end{tabular}

$R V E D A$, End-diastolic area of the right ventricle; $R V W T$, right ventricle free wall thickness; TAPSE, tricuspid annular plane systolic excursion; MSN, mesosystolic notch; $R V M / B W$, right ventricular mass normalized to corresponding body weight; $L V M / B W$, left ventricular mass normalized to corresponding body weight; $L V E D V$, left ventricular end-diastolic volume; $L V S V$, left ventricle stroke volume; $R V S V$, right ventricle stroke volume; $L V E F$, left ventricle ejection fraction; $R V E F$, right ventricle ejection fraction. $* P$ value $<.05$.

in the control (sham) group. In all rats with shunt, Qp/Qs was significantly increased $(P<.05)$ compared with the controls and demonstrating shunt patency.

\section{Echocardiographic and Magnetic Resonance Evaluation}

The RV end-diastolic area increased significantly in the shunt groups; a significant increase in the thickness of the $\mathrm{RV}$ free wall was found in both groups. There was no statistically significant difference in measured TAPSE (Table 1). A mesosystolic notch was demonstrated in the Doppler wave profile of the pulmonary flow in rats subjected to a shunt; this element was not found in the Doppler profiles of rats in the sham group (Figure 2).

The general features and major cardiac parameters obtained by MRI are shown in Table 1 . The right and left ventricular masses, expressed as normalized to corresponding body weights, as well as cardiac chambers volume increased in the shunt groups (Figure 2). However, volumes were significantly higher in the shunt $20 \mathrm{~W}$ group. Functional evaluation showed that the SV was increased in the shunt $10 \mathrm{~W}$ group and reduced in shunt $20 \mathrm{~W}$ group compared with the sham group (not significant). Furthermore, our data show a moderate reduction in the $\mathrm{EF}$ of the RV and $\mathrm{LV}$ in the shunt $10 \mathrm{~W}$ group; this reduction is significant in the shunt $20 \mathrm{~W}$ group compared with the sham group.

\section{Hemodynamic Analysis}

Left ventricle. Invasive hemodynamic analysis was performed on both LV and RV. LV end-diastolic and endsystolic volumes increased in the shunt groups. In the shunt $20 \mathrm{~W}$ group, these volumes were significantly increased compared with the controls. $\mathrm{dP} / \mathrm{dt}_{\max }$ was reduced in the shunt $20 \mathrm{~W}$ group representing a worsening of systolic function. Analysis of the P-V loops obtained during transient
IVC occlusion allowed preload-independent hemodynamic evaluation. The end-systolic pressure-volume relationship and PRSW demonstrated a decrease in contractility, which was significant in the shunt $20 \mathrm{~W}$ group.

Tau and $\mathrm{dP} / \mathrm{dt}_{\min }$ are the most accurate indexes of diastolic function: $\mathrm{dP} / \mathrm{dt}_{\min }$ decreased significantly in both shunt groups and tau increased in both shunt groups but was significantly higher compared with the controls only in the shunt $20 \mathrm{~W}$ group. These modifications suggest a worsening in diastolic ventricular function and compromised ventricular relaxation. A significant increase in LV end-diastolic pressure and a decrease in the end-diastolic pressure-volume relationship were found in the shunt groups compared with the sham group. Figure 3 summarizes the LV hemodynamic data.

Right ventricle and pulmonary artery. Both enddiastolic and end-systolic volumes increased significantly in the shunt groups. $\mathrm{dP} / \mathrm{dt}_{\max }$ was significantly reduced in the shunt 20W group; moreover, the end-systolic pressure-volume relationship and PRSW were reduced significantly in this group. $\mathrm{dP} / \mathrm{dt}_{\min }$ decreased significantly in the shunt groups, whereas tau increased, showing a worsening of RV diastolic function.

A significant increase in $\mathrm{RV}$ end-diastolic pressure and a decrease in the end-diastolic pressure-volume relationship were found in groups with an aortocaval shunt compared with the sham group. Figure 3 summarizes the RV hemodynamic data. A significant increase in systolic and diastolic pressures and a significant increase in effective pulmonary arterial elastance were found.

\section{Histologic Evaluation}

Nonsignificant medial thickening was observed in the intralobular pulmonary arteries of the shunt $10 \mathrm{~W}$ rats compared with the controls. Histologic images are shown 


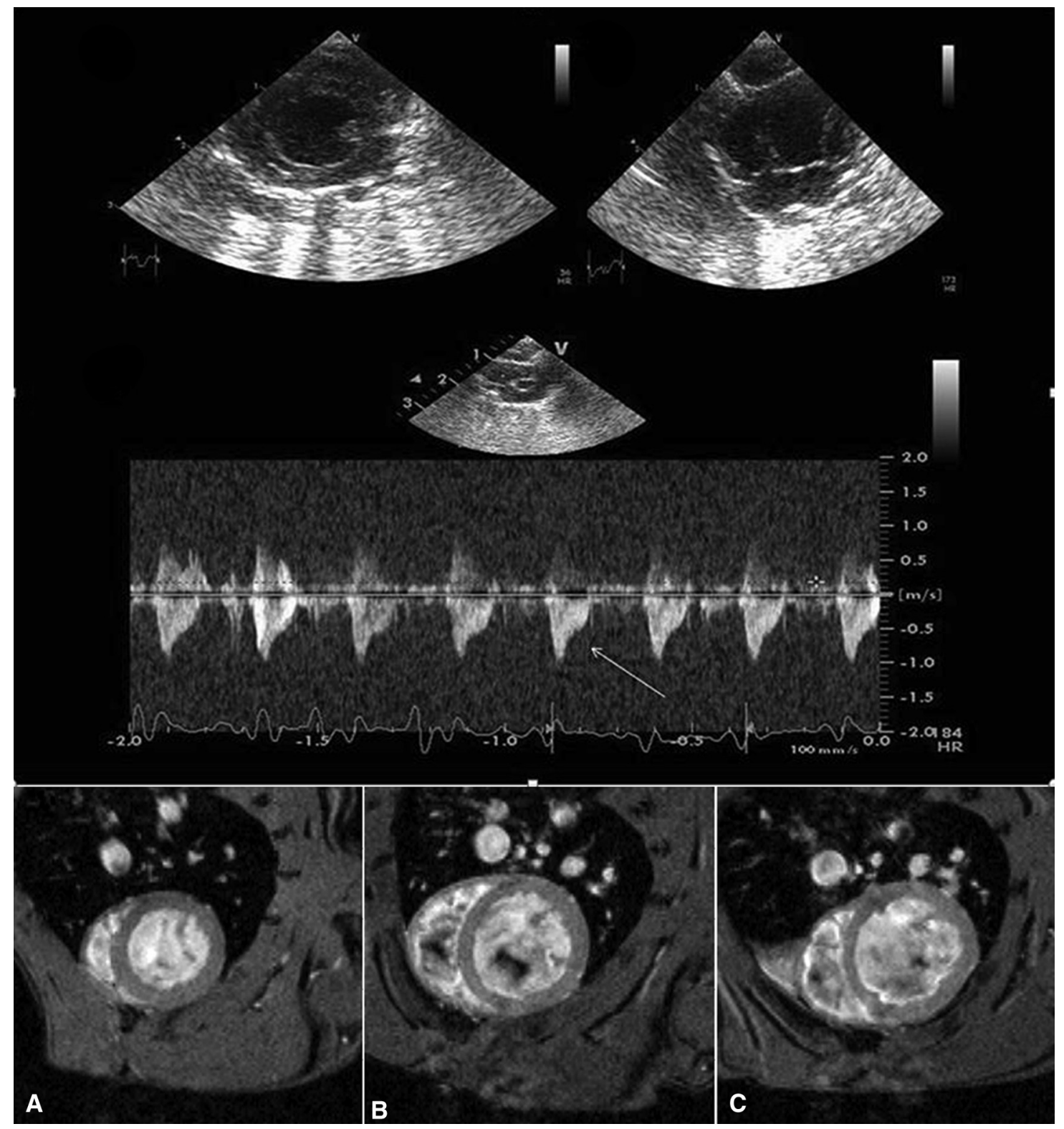

FIGURE 2. Echocardiogram: analysis of RV free wall thickness and RV end-diastolic dimension was performed in the parasternal short axis at the level of the papillary muscles. Using the apical 4-chamber projection to obtain an estimate of TAPSE (tricuspid annular plane systolic excursion). A mesosystolic notch (indicated with a white arrow) appears in the Doppler wave profile of the pulmonary flow of rats subjected to a shunt but not in the Doppler profiles of the sham group. Magnetic resonance: cardiac chamber volumes were increased in both shunt groups. A, Sham; B, shunt for 10 weeks shunt; C, shunt for 20 weeks.

in Figure 4. After 20 weeks of exposure to volume overload, thickening of the tunica media with muscular hypertrophy is evident using Masson trichrome stain; collagen appears blue between muscular cells, revealing low fibrosis. In some of the shunt $20 \mathrm{~W}$ rats, complete occlusion of the intralobular arteries was found as a result of concentric intimal hyperplasia. No advanced plexiform lesions or signs of severe and irreversible $\mathrm{PH}$ were observed.

\section{DISCUSSION}

In humans, chronic exposure to a high-pressure left-right shunt results in the development of progressive $\mathrm{PH}$ and, eventually, Eisenmenger syndrome, whereas high-volume left-right shunts rarely generate severe $\mathrm{PH}$ if left untreated. However, exceptions to this pathophysiologic principle have since been observed primarily in adults with atriallevel septal defects after 20 to 30 years of exposure to the shunt ${ }^{15,16}$ and, occasionally, even in children. ${ }^{17}$ Mechanical 

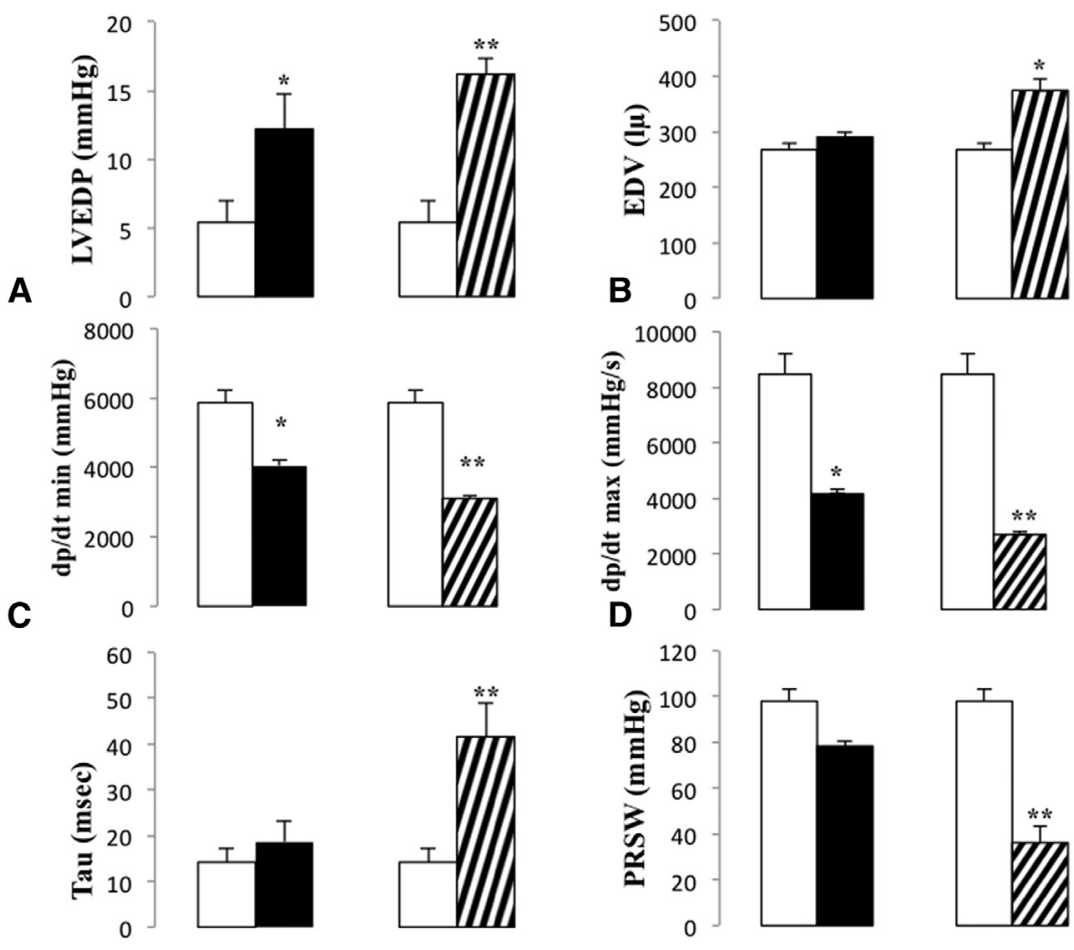

E
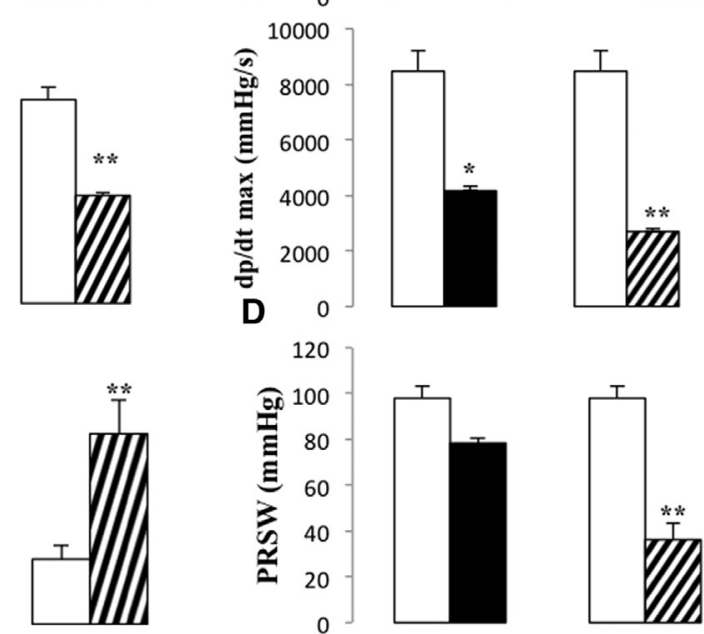

F

SHAM

SHUNT 10 WEEKS

RHUNT 20 WEEKS

${ }^{*} \mathbf{p}<0.05 * * \mathbf{p}<0.01$ are shown
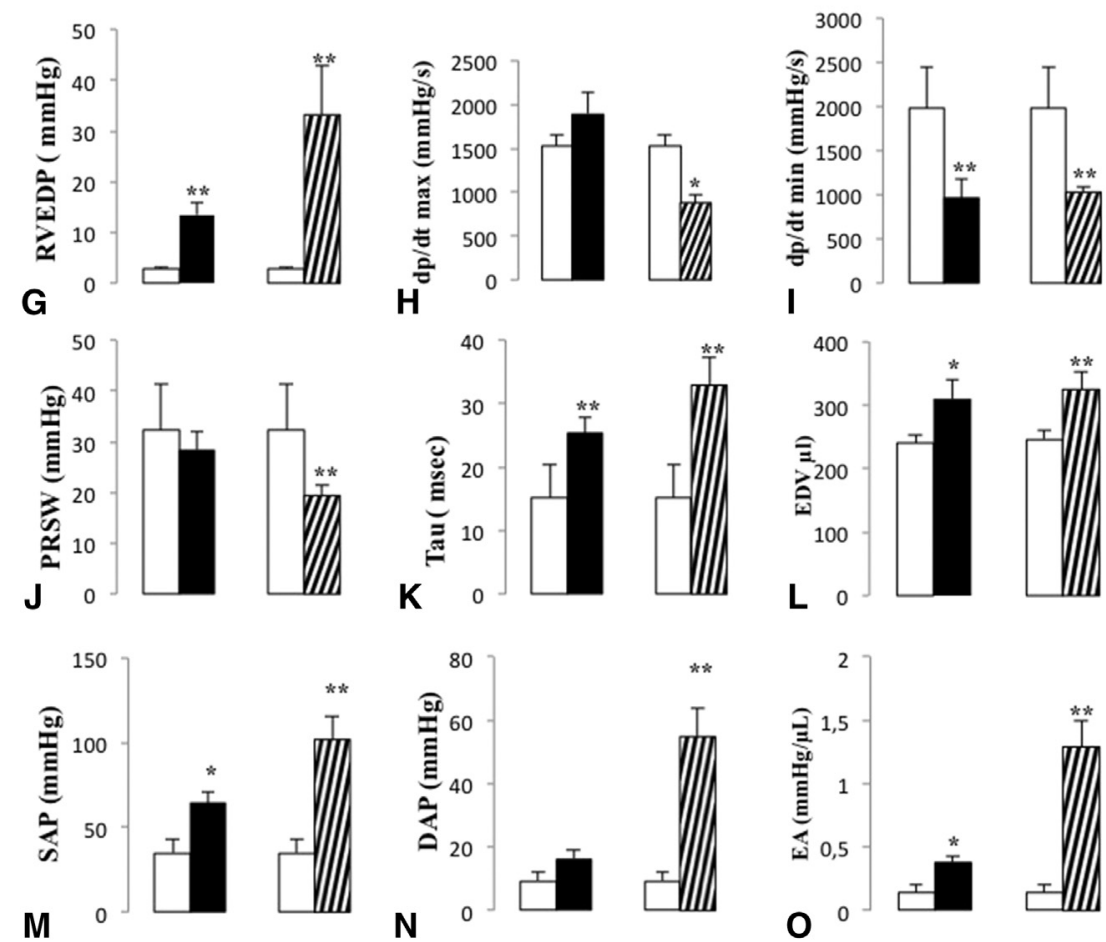

SHAM

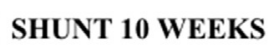

\section{展}

$$
{ }^{*} \mathbf{p}<0.05 * * \mathbf{p}<0.01 \text { are shown }
$$

FIGURE 3. A-F, Left ventricle hemodynamic data acquired by means of the conductance catheter technique. LVEDP, Left ventricle end-diastolic pressure; Tau, time constant of left ventricular pressure decay; $d P / d t_{\max }$ and $d P / d t_{\min }$, maximal peak systolic pressure increase and diastolic pressure decrease; 

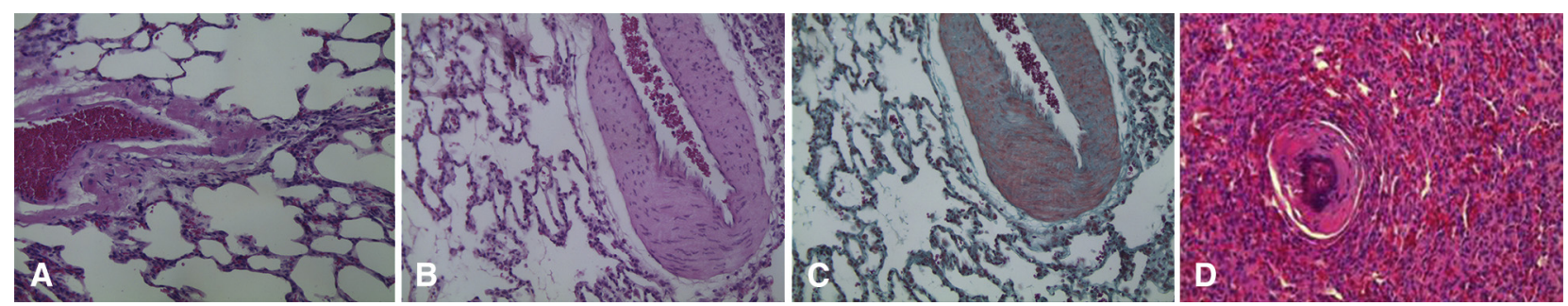

FIGURE 4. A, Normal pulmonary histology in a sham rat. B, After 20 weeks of exposure to volume overload, thickening of the tunica media with muscular hypertrophy is evident. C, Masson trichrome stain. Collagen is marked in blue between muscular cells, revealing low fibrosis. D, Complete occlusion of the intralobular arteries as a result of concentric intimal hyperplasia was found in some of rats shunted for 20 weeks.

force may be an important stimulus to remodeling of the pulmonary vasculature; the increased pulmonary blood flow could induce effective shearing stress in the pulmonary vasculature and this could be the first stimulus for the initiation of changes in the vascular wall. ${ }^{18}$

Continuous attempts have been made to simulate pulmonary vasculopathy by surgically creating peripheral arteriovenous or central systemic-to-pulmonary communications with varying and conflicting results. ${ }^{19-21}$ Therefore, the need for a satisfactory shunt-related model remains, with the aim of determining the underlying molecular mechanisms of pulmonary vascular remodeling for exposure to high blood flow in vivo.

The aortocaval shunt model is a reproducible, simple, and rapid method for developing high-output heart failure and cardiac hypertrophy. ${ }^{4}$ To the best of our knowledge, this is the first study to use noninvasive methods and a detailed hemodynamic evaluation to verify the development of pulmonary vascular remodeling and $\mathrm{PH}$ induced by an experimental model of chronic pulmonary overflow. After 10 and 20 weeks, echocardiography and MRI show a progressive increase in end-diastolic area and RV volume. Although volume overload was previously demonstrated by Garcia and Diebold, ${ }^{4}$ the 4 -week observation period was too short to induce pulmonary vascular remodeling, LV dysfunction, and secondary $\mathrm{PH}$.

In the present study, the parameters detected with echocardiographic analysis and MRI have shown progressive, ventricular, dilatative hypertrophy. Ventricular remodeling leads to worsening ventricular function, which was well studied with a P-V conductance catheter to obtain preload-dependent and independent parameters (Figure 5). A reduction in systolic and diastolic functions and contractility of the LV and RV were found.

No previous study has described the consequences of long-term exposure to aortocaval shunts. Therefore, no previous work has been able to observe the appearance of left ventricular dysfunction. Left ventricular dysfunction seems to be a late consequence of the aortocaval shunt and is probably linked to right ventricular dysfunction as a consequence of volume overload. Using MRI, we detected a leftward shift of the interventricular septum, with a roundshaped RV and compressed LV. Geometric remodeling could be a second mechanism involved in left ventricular dysfunction that, in addition to increased pulmonary blood flow and shear stress, contributes to the development of $\mathrm{PH}^{22-24}$

The progressive development of $\mathrm{PH}$ during chronic exposure to an aortocaval shunt has been demonstrated in the present study. This result is consistent with Lam and colleagues $^{25}$ who first observed the signs of $\mathrm{PH}$ in rats with an aortocaval fistula. For the first time, different hemodynamic measurements and state-of-the-art imaging were applied to address ventricular-vascular interactions in a rat pulmonary artery overflow model. The presence of a mesosystolic notch in the Doppler profile of pulmonary blood flow in the shunt $20 \mathrm{~W}$ groups suggested increased systolic pulmonary pressure as demonstrated by Jones and colleagues. ${ }^{11}$ Using a Millar catheter, $\mathrm{PH}$ was confirmed by direct measurement of increased pulmonary pressure and increased effective pulmonary arterial elastance, which is the most accurate index of pulmonary vascular load, ${ }^{26}$ and is related to the increase in pulmonary artery stiffness. ${ }^{14}$

Further evidence of the development of progressive pulmonary vascular remodeling related to hypertension in the rats was provided by histologic analysis of the lungs. Progressive thickening of the muscular lamina after shunt $10 \mathrm{~W}$ and $20 \mathrm{~W}$ groups was demonstrated. In the shunt $20 \mathrm{~W}$ group, we found complete occlusion of the intralobular arteries as a result of concentric intimal thickening (Figure 4). However, advanced plexiform lesions were not detected; in our opinion, longer exposure to the shunt could produce this sign of advanced irreversible $\mathrm{PH}$.

$E D V$, end-diastolic volume; PRSW, preload recruitable stroke work. G-O, Right ventricle hemodynamic data acquired by means of the conductance catheter technique. RVEDP, Right ventricle end-diastolic pressure; Tau, time constant of right ventricular pressure decay; $S A P$, systolic pulmonary artery pressure; $D A P$, diastolic pulmonary artery pressure; $E A$, arterial elastance. 
LV - CONTROL

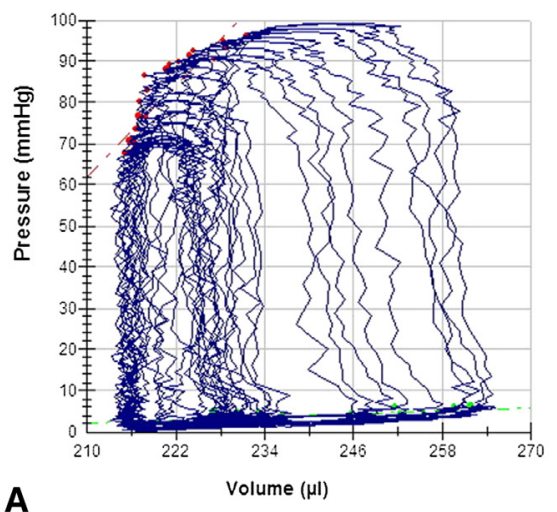

A

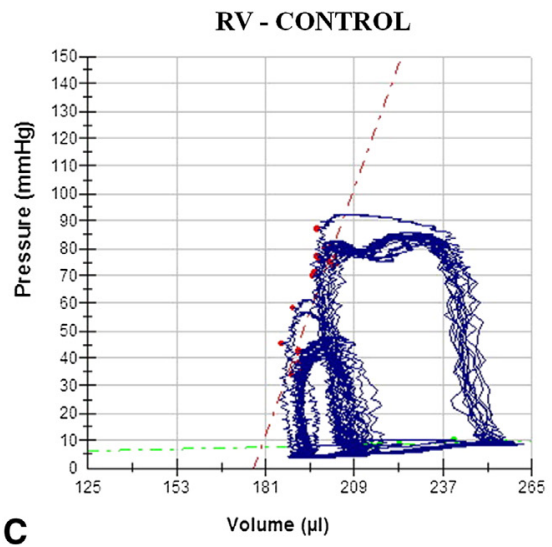

LV-SHUNT 20W

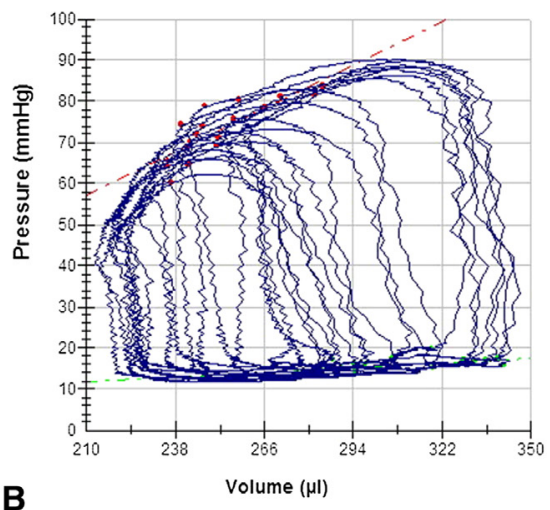

RV - SHUNT 20W

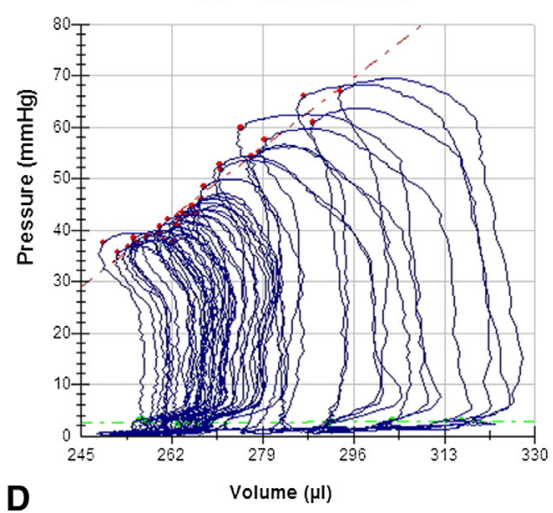

FIGURE 5. Pressure-volume loops obtained during temporary inferior vena cava occlusion in representative cases from the control group and shunt group after 20 weeks. Left ventricle $(L V)$ analysis (A and $\mathrm{B})$ and right ventricle $(R V)$ analysis $(\mathrm{C}$ and $\mathrm{D})$ are shown. The end-systolic pressure-volume relationship (red dotted line) and the end-diastolic pressure-volume relationship (green dotted line) demonstrate worsening of biventricular function.

\section{Limitations of the Study}

In the present work, the aortocaval shunt generated a $\mathrm{Qp} /$ Qs of 2, which usually describes a moderat pretricuspid shunt that rarely generates $\mathrm{PH}$ in humans. Nonetheless, clinical observations are accumulating showing how longterm exposure to atrial-level shunts may produce even severe $\mathrm{PH} \cdot{ }^{15-17}$ In addition, atrial-level shunting, with or without severe $\mathrm{PH}$, and $\mathrm{PH}$ per se have since been shown to cause LV dysfunction by a variety of mechanisms, including ventricular remodeling, decreased myofiber preload, and ventricular dyssynchrony, a phenomenon otherwise known as ventricular interdependence. ${ }^{27-29}$ The severe $\mathrm{PH}$ observed in the present experimental setting may be explained by species-specific differences, thereby representing a possible limitation to translation of the results to human pathology. However, a period of 20 weeks relative to an average life span of 2 years represents a remarkably long exposure and could explain the development of PH in this animal model.

\section{CONCLUSIONS}

Aortocaval shunt is a reliable model to study both biventricular volume overload and flow-induced $\mathrm{PH}$.
Noninvasive assessment provided by echocardiographye and MRI allows multiple functional and structural evaluations of the compensatory mechanisms of both ventricles in chronic volume overload. The present model is a reliable method to study the role of pulmonary overflow in secondary $\mathrm{PH}$ related to a pretricuspid shunt, which may be instrumental in understanding cases of atrial-level defects associated with pulmonary vascular disease.

\section{References}

1. Badesch DB, Champion HC, Sanchez MA, Hoeper MM, Loyd JE, Manes A, et al. Diagnosis and assessment of pulmonary arterial hypertension. J Am Coll Cardiol. 2009;54:S55-66.

2. Bai Y, Sun L, Hu S, Wei Y. Combination therapy in pulmonary arterial hypertension: a meta analysis. Cardiology. 2011;120:157-65.

3. Simonneau G, Galie N, Rubin LJ, Langleben D, Seeger W, Domenighetti G, et al. Clinical classification of pulmonary hypertension. J Am Coll Cardiol. 2004;43: S5-12.

4. Garcia R, Diebold S. Simple, rapid and effective method of producing aortocaval shunts in the rat. Cardiovasc Res. 1990;24:430-2.

5. Ocampo $C$, Ingram $P$, Ilbawi $M$, Arcilla $R$. Revisiting the surgical creation of volume load by aorto-caval shunt in rats. Mol Cell Biochem. 2003; 251:139-43.

6. Wang X, Ren B, Liu S, Sentex E, Tappia PS, Dhalla NS. Characterization of cardiac hypertrophy and heart failure due to volume overload in the rat. J Appl Physiol. 2003;94:752-63. 
7. Szabó G, Soós P, Bährle S, Radovits T, Weigang E, Kékesi V, et al. Adaptation of the right ventricle to an increased afterload in the chronically volume overloaded heart. Ann Thorac Surg. 2006;82:989-95.

8. Yerebakan C, Klopsch C, Niefeldt S, Zeisig V, Vollmar B, Liebold A, et al. Acute and chronic response of the right ventricle to surgically induced pressure and volume overload, an analysis of pressure-volume relations. Interact Cardiovasc Thorac Surg. 2010;10:519-25.

9. Nishimura T, Faul JL, Berry GL, Kao PN, Pearl RG. Effect of a surgical aortocaval fistula on monocrotaline-induced pulmonary hypertension. Crit Care Med. 2003;31:1213-8.

10. Van Albada ME, Schoemmaker RG, Kemna MS, Cromme-Dijkhuis AH, van Veghel R, Berger RMF. The role of increased pulmonary blood flow in pulmonary arterial hypertension. Eur Respir J. 2005;26:487-93.

11. Jones J, Mendes L, Rudd MA, Russo G, Loscalzo J, Zhang YY. Serial noninvasive assessment of progressive pulmonary hypertension in a rat model. Am J Physiol Heart Circ Physiol. 2002;283:H364-71.

12. Pacher P, Mabley JG, Liaudet L, Evgenov OV, Marton A, Hasko G, et al. Left ventricular pressure-volume relationship in a rat model of advanced agingassociated heart failure. Am J Physiol Heart Circ Physiol. 2004;287:H2132-7.

13. Weiss JL, Frederiksen JW, Weisfeldt ML. Hemodynamic determinants of the time-course of fall in canine left ventricular pressure. J Clin Invest. 1976;58: 751-60.

14. Nakano K, Sugawara M, Ishihara K, Kanazawa S, Corin WJ, Denslow S, et al. Myocardial stiffness derived from end-systolic wall stress and logarithm of reciprocal of wall thickness. Contractility index independent of ventricular size. Circulation. 1990;82:1352-61.

15. Bradley EA, Chakinala M, Billadello JJ. Usefulness of medical therapy for pulmonary hypertension and delayed atrial septal defect closure. Am J Cardiol. 2013;112:1471-6.

16. Luciani GB, Viscardi F, Pilati M, Crepaz R, Faggian G, Mazzucco A. Age at repair affects the very long-term outcome of sinus venosus defect. Ann Thorac Surg. 2008;86:153-9.

17. Goetschmann S, Dibernardo S, Steinmann H, Pavlovic M, Sekarski N, Pfammatter JP. Frequency of severe pulmonary hypertension complicating "isolated" atrial septal defect in infancy. Am J Cardiol. 2008;102:340-2.
18. Kulik TJ. Pulmonary blood flow and pulmonary hypertension: is the pulmonary circulation flowophobic or flowophilic? Pulm Circ. 2012;2:327-39.

19. Xiong M, Yao JP, Wu ZK, Liao B, Liang YJ, Zhang X, et al. Fibrosis of pulmonary vascular remodeling in carotid artery-jugular vein shunt pulmonary artery hypertension model of rats. Eur J Cardiothorac Surg. 2012;41:162-6.

20. Rondelet B, Dewachter C, Kerbaul F, Kang X, Fesler P, Brimioulle S, et al. Prolonged overcirculation-induced pulmonary arterial hypertension as a cause of right ventricular failure. Eur Heart J. 2012;33:1017-26.

21. Meng L, Liu X, Zheng Z, Li J, Meng J, Wei Y, et al. Original rat model of high kinetic unilateral pulmonary hypertension surgically induced by combined surgery. J Thorac Cardiovasc Surg. 2013;146:1220-6.

22. Alpert JS. The effect of right ventricular dysfunction on left ventricular form and function. Chest. 2001;119:1632-3.

23. Haddad F, Guihaire J, Skhiri M, Denault AY, Mercier O, Al-Halabi S, et al. Septal curvature is marker of hemodynamic, anatomical, and electromechanical ventricular interdependence in patients with pulmonary arterial hypertension. Echocardiography. 2013; http://dx.doi.org/10.1111/ echo.12468 [Epub ahead of print].

24. López-Candales A, Edelman K. Chronic pulmonary hypertension causes significant interventricular spatiotemporal dyssynchrony when onset of diastolic flow signals are assessed by color M-mode. Echocardiography. 2012;29:653-60.

25. Lam CF, Peterson TE, Croatt AJ, Nath KA, Katusic ZS. Functional adaptation and remodeling of pulmonary artery in flow-induced pulmonary hypertension. Am J Physiol Heart Circ Physiol. 2005;289:H2334-41.

26. Morimont P, Lambermont B, Ghuysen A, Gerard P, Kolh P, Lancellotti P, et al Effective arterial elastance as an index of pulmonary vascular load. Am J Physio Heart Circ Physiol. 2008;294:H2736-42.

27. Walker RE, Moran AM, Gauvreau K, Colan SD. Evidence of adverse ventricular interdependence in patients with atrial septal defects. Am J Cardiol. 2004;93: 1374-7.

28. Hardegree EL, Sachdev A, Fenstad ER, Villarraga HR, Frantz RP, McGoon MD et al. Impaired left ventricular mechanics in pulmonary arterial hypertension: identification of a cohort at high risk. Circ Heart Fail. 2013;6:748-55.

29. Haeck ML, Höke U, Marsan NA, Holman ER, Wolterbeek R, Bax JJ, et al. Impact of right ventricular dyssynchrony on left ventricular performance in patients with pulmonary hypertension. Int J Cardiovasc Imaging. 2014;30:713-20. 